\title{
Blue-bloods of the sea
}

\author{
by Monica Harrington
}

SCIENTIFIC NAME

Limulus polyphemus

TAXONOMY

PHYLUM: Arthropoda

CLASS: Merostomata

ORDER: Xiphosura

FAMILY: Limulidae

\section{Physical description}

Atlantic horseshoe crabs are most commonly found on shallow ocean floors in the Gulf of Mexico and along the northeastern coast of the US. Despite their common name, horseshoe crabs are not crustaceans but marine arthropods, closely related to arachnids.

The horseshoe crab's body is protected dorsal-

ly by a smooth, hard carapace that ranges

from greenish gray to dark brown in color. Females are larger than males, with total body length up to $20 \mathrm{in}$. The body is rounded in shape like a horseshoe (hence, the name) and features a long caudal spine or telson, which the crab uses to steer in the water, to propel itself along the sea floor and to right itself when turned on its back. The head holds most of the animal's organs, including heart, brain and mouth. The horseshoe crab's legs are used for locomotion and feeding. The middle segment of each leg is covered with spines that grind food before passing it into the mouth, located in the center of the legs. The crab must be moving in order to 'chew. The abdomen is lined with movable spines for protection and houses the muscles and gills. Horseshoe crabs generally move along the ocean bottom but can swim, although they do so upside down ${ }^{1}$.

Horseshoe crabs have nine eyes distributed around the body: two compound eyes and seven simple eyes, along with a group of photoreceptors clustered near the tail. They have the largest rods and cones of any known animal, but their vision is relatively poor.

\section{Research résumé}

Despite their poor vision, horseshoe crabs have contributed greatly to visual research ${ }^{2}$, owing to the large size and accessibility of the compound eyes and optic nerve and to the simple organization of the visual system. Haldan Keffer Hartline discovered lateral inhibition in horseshoe crabs $^{3}$ and was awarded the Nobel Prize in Physiology or Medicine in 1967 for his work. In presenting the

Nobel Prize, C.G. Bernhard lauded Hartline's "careful choice of a suitable object-the eye of the horseshoe crab" (http://www.nobelprize.org/nobel_prizes/medicine/laureates/1967/press.html).

But the horseshoe crab's blood, rather than its vision, is arguably its most famous feature. The blood contains copper-based hemocyanin to carry oxygen, which gives it a unique sky-blue color. The sole blood cells, called amebocytes, defend the crab against pathogens, including bacteria that are omnipresent in seawater. To prevent infection from spreading, the crab's amebocytes form clots in response to bacterial endotoxin. Exposure to endotoxin causes severe health problems in humans. Scientists realized that the clotting or coagulation activity of horseshoe crab amebocytes could be used to indicate the presence of endotoxin in devices or drugs intended for internal or intravenous use, protecting humans from potential exposure. This Limulus amebocyte lysate (LAL) test has been used for decades to test drugs and equipment for contamination; no other test works as well or as quickly. But it requires large quantities of horseshoe crab blood, which must be collected from living animals. Although most of the crabs are returned to the sea and survive, mortality may be as high as $30 \%$ and blood collection has sublethal effects as well ${ }^{4}$. Alternatives to LAL for the detection of endotoxin for medical purposes are being pursued in order to reduce the use of horseshoe crabs in these applications. One group of researchers created synthetic versions of antibacterial peptides found on the skin of the African clawed frog and incorporated them into a small electronic chip that emits an electrical signal in response to harmful bacteria ${ }^{5}$. Another group produced a recombinant form of the coagulation enzyme present in LAL that can be packaged as a diagnostic assay for endotoxin screening ${ }^{6}$.

1. Vosatka, E.D. Observations on the swimming, righting, and burrowing movements of young horseshoe crab, Limulus polyphemus. Ohio J. Sci. 70, 276-283 (1970).

2. Liu, J.S. \& Passaglia, C.L. Using the horseshoe crab, Limulus polyphemus, in vision research. J. Vis. Exp. doi:10.3791/1384 (published online 3 July 2009).

3. Hartline, H.K., Wagner, H.G., Ratliff, F. Inhibition in the eye of Limulus. J. Gen. Phys. 39, 651-673 (1956).

4. Anderson, R.L., Watson, W.H. III \& Chabot, C.C. Sublethal behavioral and physiological effects of the biomedical bleeding process on the American horseshoe crab, Limulus polyphemus. Biol. Bull. 225, 137-151 (2013).

5. Mannoor, M.S., Zhang, S., Link, A.J. \& McAlpine, M.C. Electrical detection of pathogenic bacteria via immobilized antimicrobial peptides. Proc. Natl. Acad. Sci. USA 107, 19207-19212 (2010).

6. Ding, J.L. \& Ho, B. Endotoxin detection-from limulus amebocyte lysate to recombinant factor C. Subcell. Biochem. 53, 187-208 (2010). 